\title{
The acceptability of counter-terrorism measures on urban mass transit in the UK
}

\author{
J. G. Kappia ${ }^{1}$, D. Fletcher ${ }^{2}$, L. Bosher ${ }^{1}$ \& J. P. Powell ${ }^{2}$ \\ ${ }^{I}$ Department of Civil and Building Engineering, \\ Loughborough University, Loughborough, UK \\ ${ }^{2}$ NewRail, Faculty of Science, Agriculture and Engineering, \\ Newcastle University, Newcastle upon Tyne, UK
}

\begin{abstract}
The security and safety of urban mass transit systems continues to draw a great deal of government, media and public attention. The bombings in Madrid, London and Mumbai, suggest that new and "acceptable" approaches to counterterrorism may become important components of how urban mass transit systems are designed and operated in the future. Technical developments in security and counter-terrorism can provide a wide range of non-intrusive or overt design solutions to counter-terrorism. However, in implementing these design solutions the whole system performance needs to be considered. Undertaking qualitative research with a wide range of stakeholders (including the public, transit system designers and operators) the potential acceptability of certain technological approaches is assessed. Analysis of the findings suggests five broad acceptability factors governed by five influence variables. The acceptability factors include that counter-terrorism measures are more acceptable to transit designers and operators if they are tied in with complementary personal security and safety features, and are more acceptable to transit operators and the general public if they do not restrict the free flow of passengers through the transit network. These perspectives are dependent upon influence variables including whether there was a recent attack on a UK transit system and the Government's present 'level of threat' from terrorist attack. The impact of these findings is discussed along with suggestions for future research into acceptable counter-terrorism measures for transport.
\end{abstract}

Keywords: mass rail transit, counter-terrorism, security, acceptability, UK. 


\section{Introduction - acceptability of counter terrorism measures}

Urban Mass Transportation systems (UMT) are vital to meet society's demands for rapid transport of people into and out of cities. The recognised objective of many known terrorist organisations is to carry out disruptive acts and in so doing cripple the economy of the respective service, community or nation. These acts include the usage of explosives to cause damage and infuse terror among the public. Many industries become victim to these acts and suffer a full range of losses owing to damage, uncertainty and fear. Across Europe millions of people travel daily on UMT systems, and by design, such systems must be open and accessible, which has the confounding factor of making them difficult to secure. As such rail transit is considered an attractive target, highlighting the importance of rail security for staff and passengers alike [10].

Over recent years terrorists have demonstrated the ability to change strategies and tactics in response to security measures. As a result, transport officials and policy makers need to adapt in order to protect the public. However "acceptability" is an important concept in the implementation of changes to a system. Different stakeholders will have a range of views and perceptions as to what is acceptable, depending on their role (for example manager, security personnel, passenger or otherwise) and their personal judgements. These can all change over time, in response to particular events and different countries may have differing standards as to what is acceptable. In addition, acceptability is just one factor in the adoption of Counter-Terrorism (CT) measures, and hence must be considered alongside other factors such as cost and performance in the context of the integrated system.

The literature and research reported in this paper aims to introduce the counter-terrorism acceptability issue in respect of urban mass transit and light rail systems. Using a combination of data from focus groups, case studies and semi-structured interviews a broad picture is painted of the issues relevant to stakeholders which will provide the basis of further empirical works. It is worth noting that the focus of the research is on vehicles and stations as "crowded places', rather than on infrastructure such as depots, power supplies and remote installations.

\section{The emerging debate - terrorist threats and public perceptions}

The issue of terrorist threat to rail systems is real, current and pervasive, but attacks against railways date back to the first rail system in the $19^{\text {th }}$ century. In recent years an increasing number of high profile incidents emphasise the importance in raising awareness of the issues involved.

\subsection{A provenance of rail terror attacks}

A statistical summary compiled from the US Government Global Terrorism Database [9] shows that bombings are by far the most common type of attack 
against rail systems, accounting for almost $90 \%$ of all incidents. The most common targets are 'crowded places' such as stations and passenger trains with only $7 \%$ of attacks directed against infrastructure.

The majority of documented attacks however are relatively small in scale. Typical of these are the PIRA (Provisional Irish Republican Army) campaign on mainland Britain during the 1990s. The most serious incidents were at London's Victoria Station on $18^{\text {th }}$ February 1991, where one person was killed and 38 injured by a bomb planted in a litterbin, and at London Bridge station on $28^{\text {th }}$ February 1992 where 29 people were injured [2]. During this period there were 41 actual bombs compared with over 6700 bomb threats made against the railways; additionally there were over 9500 suspicious items left on the railway system that required the attention of the UK police [5]. In this case, the aim of the campaign was primarily to cause disruption rather than casualties.

More recently there has been a shift from smaller scale attacks intending to cause only disruption (such as the PIRA campaign) towards mass casualty events, as well as the emergence of suicide bombers. This represents 'a different brand of terrorism' [10] with coordinated attacks on a much larger scale than previously experienced and on multiple targets. Importantly, avoidance of capture is often of little concern in these attacks, which are conducted by determined individuals after meticulously planning

The bombings of commuter trains in Madrid on $11^{\text {th }}$ March 2004 (killing 191 people and injuring 1841 [3]) and the suicide bombers in London on $7^{\text {th }}$ July 2005 (52 deaths and over 770 injuries [4]) are recent examples of rail attack strategies. The sarin gas attack on the Tokyo Subway on $20^{\text {th }}$ March 1995 was proclaimed the dawn of a new age of 'catastrophic' terrorism involving chemical, biological, and nuclear weapons' [1]. In all, 12 people were killed, and over 5000 injured with varying degrees of severity [2], although the psychological effects and uncertainty surrounding an attack with an unconventional weapon are harder to quantify. With few exceptions these attacks have involved major injuries and casualties to the public, and in light of these trends, crowded places should continue to be seen as priority cases for the introduction of counter-terrorist measures.

\subsection{Reaction priorities in light of the changing nature of terror objectives}

Just as terrorist tactics have changed, the response to terrorist attacks has also changed, now focussing on fast recovery of the system rather than merely the development of measures to reduce vulnerability to attack. This highlights an important distinction in CT measures, between an 'active' and 'passive' approach [11]. Active measures require sustained input from the system operators (with consequent costs), for example the provision of security staff and the associated resources required (equipment, communications, control rooms and so forth). Passive measures are generally environmental features that are either designed-in or retro-fitted, that require no further input; for example materials choices, or layout and structure of buildings, vehicles or infrastructure. Historically, CT strategies have been focussed on active measures against the 
terrorist threat, such as policing; these are now well developed after experience with the PIRA campaign [12]. There is now more potential for development of passive measures, i.e. designing the system in a particular way to make an attack more difficult, minimise damage from an attack and recover quickly (and also to make the active measures in place more effective). This has been termed 'designing-in resilience'; to help prevent, protect and prepare systems against terrorist attack [28].

\subsection{Business case for counter-terrorism measures}

Notwithstanding the events highlighted above, terrorist attacks are of relative low frequency; therefore it can be difficult to build a business case for adoption of CT measures. The resources for CT are limited and are in competition with other issues within the rail system as a whole (for example for funds) [10]. Therefore, decisions about spending should be based on a sound assessment of the risks to the system, and effectiveness of proposed measures in mitigating these risks [6].

One concept to consider here is 'dual-use', where CT measures have other benefits to the system too [7]; for example increased policing in response to a terrorist threat can also help decrease crime, or a choice of bomb-resistant materials can also improved fire safety. However, there are vast arrays of threats and hazards that may conflict with $\mathrm{CT}$ measures and so the impact of all potential measures should be analysed [8].

\subsection{Acceptability of counter-terrorism measures}

Acceptability is highly a subjective concept and hence cannot easily be quantified in scientific terms. In the macro-analysis $\mathrm{CT}$ can only be considered alongside other prevalent issues. In a publicly utilised and functional space an overarching concern would be service efficiency. The introduction of continuingly changing $\mathrm{CT}$ features (in light of new threats), raises the utilitarian concerns of practicality, aesthetics, efficiency, impact on the travelling public, ultimate cost and other such factors. This raises the argument of what is and what is not acceptable for the different parties involved.

It is an overriding expectation that UMT systems should be well organised and maintained and that this extends to the organisation and operation of security measures and features. However, increasingly across nations the UMT systems are owned and managed by a number of competing commercial operators with varying management systems. In such an environment, market forces apply, resulting in operators pursuing their own goals, possibly at the expense of public requirements [23]. Consequently, enthusiastic rhetoric is not always matched by firm action due to the often costly implications of CT measures. An acceptable balance must be struck between level of risk to a system and the mitigation response; investigating the potential acceptability of certain technological approaches is a key component of understanding this balance. 


\section{Methodology}

The data reported in this paper forms the initial part of a multiphase research project. The scoping study employed four particular approaches to determine the state of CT on urban mass transit systems; these included a literature review, workshops, semi-structured interviews and focus groups. Data gathering was deliberate and extensive across the UK and Europe, ensuring that a variety of perspectives were included.

Within research it is often considered necessary to conduct scoping studies to assess the relevance and size of the literature and to delimit the subject area or topic [26]. Such studies need to consider cross-disciplinary perspectives and alternative ways in which a research topic has previously been tackled. In much qualitative research the analytical process begins during data collection as the data already gathered are analysed and shape the ongoing data collection This sequential analysis [24] or interim analysis [2] has the advantage of allowing the researcher to go back and refine questions, develop hypotheses, and pursue emerging avenues of inquiry in further depth. The choice of a mixed-mode approach was made: 1) to compensate for the complexity of the subject matter; and 2) formed a convenient tool to gather concise and acceptable data from multiple sources. The data presented below is a consolidation of data collected from sixty-five key stakeholders from transport, police, built environment and CT practitioners.

\section{Results and discussion}

The study participants were formed from convenience samples across thirty interviews, three focus groups and two workshops (use of more rigorously selected samples may be pursued in later work). In each case, the brief synopsis of counter terrorism methods and initiatives offered by Table 1 was used as a basis for discussion, and was itself further developed during the discussions.

The data from interviews, focus groups and workshops was content analysed for emergent themes driving the decisions made by the various stakeholders. As the complexity of issues surrounding counter-terrorism grows (for example, with the potential for a legal requirement to consider CT in system design and operation) the need grows for a rational decision-making model, system or framework to assist transport operators. The perspective from which the analysis presented here was conducted was therefore to identify themes useful in developing support for those who must make decisions about counter-terrorism in a rail transport context. The results illustrate the acceptability issues for counter-terrorism measures in light rail systems for both staff and owners/ operators of the system, as well as the general public.

\subsection{Acceptability factors and influence variables}

Analysis of the discussions during the interviewees and focus groups has highlighted five broad acceptability factors as determined by five influence variables. Acceptability factors stipulate that counter-terrorism features are: 
Table 1: $\quad$ Counter-terrorism methods and initiatives.

\begin{tabular}{|l|l|}
\hline \multicolumn{1}{|c|}{$\begin{array}{c}\text { CT } \\
\text { Methods }\end{array}$} & \multicolumn{1}{c|}{ Calibrated Responses } \\
\hline $\begin{array}{l}\text { Baggage } \\
\text { Screening }\end{array}$ & $\begin{array}{l}\text { This has been trialled on the railway network. However, the sheer } \\
\text { number of people using rail transport every day means that } \\
\text { screening every passenger is not realistic or possible without } \\
\text { drastically changing passenger experience }\end{array}$ \\
\hline $\begin{array}{l}\text { Armed } \\
\text { Security }\end{array}$ & $\begin{array}{l}\text { While the presence of security staff is generally welcomed, } \\
\text { deploying heavily armed soldiers has led to public resistance, as it } \\
\text { can contribute to an atmosphere of fear. Use has therefore } \\
\text { provoked some controversy. }\end{array}$ \\
\hline $\begin{array}{l}\text { Advanced } \\
\text { Security }\end{array}$ & $\begin{array}{l}\text { Highly visible (or even oppressive) counter-terrorism security } \\
\text { measures might increase security, but can also promote a climate } \\
\text { of fear among passengers, as with some of the reactions to the } \\
\text { 'ring of steel in the City of London in response to PIRA } \\
\text { bombings }\end{array}$ \\
\hline $\begin{array}{l}\text { Blast } \\
\text { proofing }\end{array}$ & $\begin{array}{l}\text { The use of blast resistant materials is welcomed although requires } \\
\text { consideration of the cost implications, impact on vehicle weight } \\
\text { and many other factors }\end{array}$ \\
\hline $\begin{array}{l}\text { Sensory } \\
\text { Devices }\end{array}$ & $\begin{array}{l}\text { Sensory devices may be welcomed if proven to be efficient (no } \\
\text { false alarms), effective (fit for purpose) and unobtrusive. The cost } \\
\text { implications are hard to assess for CNBR equipment as there have } \\
\text { so far been no attacks of this type on UK systems }\end{array}$ \\
\hline Litter Bins & $\begin{array}{l}\text { Explosive devices may be hidden in litter receptacles so design of } \\
\text { these from a counter-terrorism perspective was welcome. In most } \\
\text { cases the removal of litter bins would unduly inconvenience } \\
\text { passengers, hence is unacceptable } \\
\text { acceptable. However, there is resistance to widespread coverage of } \\
\text { such systems, on the grounds that constant surveillance erodes } \\
\text { civil liberties }\end{array}$ \\
\hline
\end{tabular}

a) more acceptable to transit designers and operators if they are tied in with complementary non-terrorism related personal security and safety features;

b) acceptable to transit operators and the general public if they do not restrict the free flow of passengers through the transit network (e.g. not based on airport style security barriers);

c) more acceptable if the measures are non-intrusive and do not unduly portray an image of a system 'under attack';

d) more acceptable to service operators if the providers themselves may be held accountable for lapses in security; and 
e) more acceptable where benefits are perceived to outweigh the cost of implementation.

The influence variables determine that decisions to integrate counterterrorism measures are dependent on:

1) whether there was a recent attack on a UK transit system;

2) the Government's present 'level of threat' from terrorist attack;

3) media coverage of global terrorism issues;

4) when security precautions were last updated; and

5) influence of relevant stakeholder group (relative power/authority/engagement of the individual or organisation).

\subsection{Directions of future research}

In addition to informing the development of a decision support framework for those who must implement $\mathrm{CT}$ measures, the acceptability and influence results can be used to highlight the future directions for more technical research. Recent acts of terror have increased the interest in understanding a range of extreme events and planning for their occurrence, for example flooding and other natural phenomena as well as terrorism [29]. Against this background, designing-in resilience to attack is one area where there is significant scope for development. For example this may be through choice of construction materials, layout, structure and through 'passive' technologies which can cost effectively be designed-in to rail vehicles and infrastructure. Other areas of potential further research include scanning and detection technology, a greater understanding of possible CBRN attacks and in-transit security of hazardous goods, intelligent CCTV monitoring, crowd dynamics, behavioural analysis and other psychological issues. A factor not highlighted above, but which was raised by several respondents, is that transport systems, their stations, critical infrastructure and vehicles are often privately owned, and effective protection against all forms of hazard, including terrorism, depends on an effective partnership between business community and government [30]. Research into effective implementation of technological solutions is therefore also of importance in this complex environment.

\section{Conclusions and directions for further research}

This study is the result of discussions with 65 stakeholders in the rail and urban rapid transit field. Data was gathered through thirty interviews, three focus groups and two workshops. From the data the acceptability of certain technological approaches to counter-terrorism for urban rail systems was assessed. A brief summary of current counter terrorism methods and initiatives for rail systems was used as a basis for the interviews, and was itself further developed during the discussions. 
The analysis of responses showed that implementation of counter-terrorism measures relies on five broad acceptability factors which in turn are dependent upon five influence variables. Due to the exploratory nature of the research and it's relatively wide scope the results can be taken as a general analysis of the issues involved. However the overall picture that emerges is a reflection of the contexts in which decisions are made, but also indicates a low level of preparedness for terrorist attack. The results highlight a relative lack of confidence and the limited plans that exist to deal with threats to systems. Furthermore, the limited measures that have been put in place to deal with this threat are largely reactive in nature. The findings suggest that future research on implementation of CT for transport systems must seek unobtrusive, low cost solutions, ideally with 'dual benefits' in areas such as personal security, or the performance of the system in other extreme conditions such as natural disasters. Continued research in this area will serve to give transport operators a guide to help evaluate their systems and determine the best, and most efficient, ways to improve counter terrorism security.

\section{References}

[1] Smithson A, Levy L-A; "Ataxia: The Chemical and Biological Terrorism Threat and the US Response"; The Henry L Stimson Center, Report no. 35; October 2000

[2] Cherry C, Loukaitou-Sideris A, Wachs M; "Subway Station Design and Management: Lessons from Case Studies of Contemporary Terrorist Incidents"; Journal of Architectural and Planning Research, Vol. 25:1 (Spring 2008), pp. 76-90

[3] "Madrid Train Attacks in Depth"; BBC News Special Report; 2004; http://news.bbc.co.uk/1/hi/in_depth/europe/2004/madrid_train_attacks/defa ult.stm

[4] "Report of 7 July Review Committee"; Greater London Authority; June 2006

[5] Whent P; "Control of Public Space"; APTA 1999 Rapid Transit Conference Proceedings

[6] Mueller J; "The Quixotic Quest For Invulnerability: Assessing The Costs, Benefits, And Probabilities Of Protecting The Homeland"; National Convention of the International Studies Association San Francisco, California, March 26th-29th, 2008

[7] Gadomski C, Lewis M; "Future Partnerships in critical Infrastructure protection"; International Conference on Critical Infrastructure Protection, Helsinki, 4th-5th October 2007

[8] Appleton Inquiry; "Report of an inquiry into health and safety aspects of stoppages caused by fire and bomb alerts on London Underground, British Rail and other mass transit systems"; Health and Safety Executive; 1992

[9] "START Global Terrorism Database"; U.S. Department of Homeland Security; 2008; http://www.start.umd.edu/data/gtd/ 
[10] Taylor B, Loukaitou-Sideris A, Liggett R, Fink C, Wachs M, Cavanagh E, Cherry C, Haas P J; "Designing and Operating Safe and Secure Transit Systems: Assessing Current Practices in the United States and Abroad"; Mineta Transportation Institute, Report 04-05; November 2005

[11] Loukaitou-Sideris A, Taylor B, Fink C; "Rail Transit Security in an International Context: Lessons from Four Cities"; Urban Affairs Review, Vol. 41, No. 6, July 2006, pp. 727-748

[12] Jenkins B, Gersten L; "Protecting Public Surface Transportation Against Terrorism and Serious Crime: Continuing Research on Best Security Practices"; Mineta Transportation Institute, Report 01-07; September 2001

[13] "Report of 7 July Review Committee"; Greater London Authority; June 2006

[14] “Responsibilities of Transport Security's Land Transport Division"; UK Department for Transport; London

[15] "Light Railway Security - Recommended Good Practise"; Transport Security and Contingencies Directorate, UK Department for Transport; January 2007

[16] "National CCTV Strategy"; Home Office; October 2007

[17] Schneier B; "CCTV doesn't keep us safe, yet the cameras are everywhere"; The Guardian; 26th June 2008

[18] Jenkins B, Butterworth B; "Selective Screening of Rail Passengers"; Mineta Transportation Institute, Report 06-07; February 2007

[19] Lee H K; "On guard on the tracks - Armed with automatic weapons, highprofile SWAT teams patrol BART trains"; San Francisco Chronicle; 23rd October 2004

[20] Casciani D; "Shoot-to-kill policy under debate"; BBC News; 8th November 2007

[21] Coaffee J; "Terrorism, Risk and the City - The Making of a Contemporary Urban Landscape"; Ashgate, Aldershot; 2003

[22] Schneier B; "The Psychology of Security"; 18th January 2006; http://www.schneier.com/essay-155.html

[23] Custance, N. D. E (1998) “Counter Terrorism - Protecting the Nations Infrastructure”. Security Technology, 1998. Proceedings 32nd Annual 1998 International Carnahan Conference on Publication Date: 12-14 Oct 1998. PP: 19-23

[24] Becker HS (1971). Sociological work. London: Allen Lane Publishing.

[25] Miles M, Huberman A. Qualitative data analysis. London: Sage, 1984.

[26] Tranfield, D., Denyer, D., Smart, P. (2003), “Towards a methodology for developing evidence-informed management knowledge by means of systematic review", British Journal of Management, Vol. 14 pp.207-22.

[27] Nassar-McMillan, Sylvia and Borders, L. DiAnne (2002), Use of Focus Groups in Survey Item Development. The Qualitative Report, Volume 7, Number 1 March, 2002.

[28] Coaffee J., Moore, C., Fletcher D., and Bosher L.S., (2008) 'Resilient design for terror-resistant cities: Effective and acceptable solutions for 
community safety', The Proceedings of the Institution of Civil Engineers: Municipal Engineer, Vol.161, No.2, pp.103-110

[29] Barker. K., and Haimes. Y. Y (2009) "Assessing uncertainty in extreme events: Applications to risk-based decision making in interdependent infrastructure sectors" Reliability Engineering and System Safety 94 (4): $819-829$

[30] Rothery, M. (2005), "Critical infrastructure protection and the role of emergency services", The Australian Journal of Emergency Management Vol. 20 No. 2 pp. 45-50. 